University of North Florida

UNIVERSITY of

NORTH FLORIDA.

UNF Digital Commons

Chemistry Faculty Publications

Department of Chemistry

2006

\title{
Pressure Induced Octahedral Tilting Distortion in Ba2YTaO6
}

Michael W. Lufaso

University of North Florida, michael.lufaso@unf.edu

René B. Macquart

Yongjae Lee

Thomas Vogt

Hans-Conrad zur Loye

Follow this and additional works at: https://digitalcommons.unf.edu/achm_facpub

Part of the Chemistry Commons

\section{Recommended Citation}

Lufaso, Michael W.; Macquart, René B.; Lee, Yongjae; Vogt, Thomas; and zur Loye, Hans-Conrad, "Pressure Induced Octahedral Tilting Distortion in Ba2YTaO6" (2006). Chemistry Faculty Publications. 6.

https://digitalcommons.unf.edu/achm_facpub/6

This Article is brought to you for free and open access by the Department of Chemistry at UNF Digital Commons. It has been accepted for inclusion in Chemistry Faculty

Publications by an authorized administrator of UNF

Digital Commons. For more information, please contact

Digital Projects.

(C) 2006 All Rights Reserved

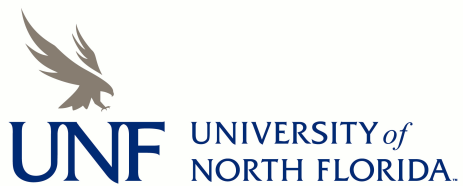




\title{
Pressure induced octahedral tilting distortion in $\mathrm{Ba}_{2} \mathrm{YTaO}_{6} \dagger$
}

\author{
Michael W. Lufaso, ${ }^{a}$ René B. Macquart, ${ }^{a}$ Yongjae Lee, ${ }^{b}$ Thomas Vogt ${ }^{a}$ and Hans-Conrad zur Loye ${ }^{* a}$
}

Received (in Cambridge, UK) 13th September 2005, Accepted 20th October 2005

First published as an Advance Article on the web 18th November 2005

DOI: $10.1039 / \mathrm{b512861g}$

\begin{abstract}
Herein we communicate the first example of a pressure induced octahedral tilting distortion in a double perovskite phase, which was observed during the structural characterization of $\mathrm{Ba}_{2} \mathrm{YTaO}_{6}$ using high-pressure synchrotron X-ray powder diffraction.
\end{abstract}

Perovskites and structurally related oxides have been one of the most widely studied structure types because of their interesting physical properties and extensive structural diversity. The per ovskite oxide has the general stoichiometry $\mathrm{ABO}_{3}$ and is composed of corner sharing $\mathrm{BO}_{6}$ octahedra with the A site cation occupying the void created by the three dimensional octahedral framework. Although many compounds adopt the ideal cubic perovskite aristotype, most perovskites undergo a distortion away from the high symmetry cubic structure. ${ }^{1}$ It is these subtle structural distortions, such as a cooperative octahedral tilting distortion that occurs when the A site cation is undersized for the corner sharing network, that often greatly influence the physical properties. Research on ordered double perovskites has been pursued by a large number of researchers, in part, because of the diverse physical properties and remarkable structural chemistry observed in these materials. Octahedral tilting in cation ordered double perovskites has been examined in detail by several groups using a number of techniques, including group theoretical analysis. ${ }^{2}$ While temperature is the most common intensive variable utilized in the study of phase transitions in these materials, pressure also may induce a structural phase transition; an example being the first order rhombohedral $(R \overline{3})$ to monoclinic $(I 2 / m)$ transition in $\mathrm{Ba}_{2} \mathrm{BiTaO}_{6}$ that can be induced by either lowering the temperature or through the application of pressure. ${ }^{3}$ Here we describe the first example of a pressure induced octahedral tilting distortion in $\mathrm{Ba}_{2} \mathrm{YTaO}_{6}$, observed by variable pressure synchrotron $\mathrm{X}$ ray powder diffraction, which demonstrated that $\mathrm{Ba}_{2} \mathrm{YTaO}_{6}$ under goes a pressure induced phase transition between 4.3 and $5.6 \mathrm{GPa}$ from space group $F m \overline{3} m$ to space group $I 4 / m$ with the onset of an octahedral tilting distortion.

In situ high pressure synchrotron $\mathrm{X}$ ray powder diffraction experiments on $\mathrm{Ba}_{2} \mathrm{YTaO}_{6}$ \%ere performed using a diamond anvil cell at the X7A beam line at the National Synchrotron Light Source at Brookhaven National Laboratory. $\$$ The experimental setup and detailed procedure are described elsewhere. ${ }^{4}$ Diffraction

${ }^{a}$ Department of Chemistry \& Biochemistry, University of South

Carolina, 631 Sumter St. Columbia, SC 29208, USA.

E mail:zurloye@mail.chem.sc.edu; Fax: +1 (803) 777 8508;

Tel: +1 (803) 7776916

${ }^{b}$ Department of Earth System Sciences, Yonsei University, Seoul,

120749, South Korea

$\uparrow$ Electronic supplementary information (ESI) available: tables containing the pressure dependence of the peak FWHM and refined crystal structures. See DOI: 10.1039/b512861g patterns were collected using a wavelength of $0.62245 \AA$. Diffraction data analysis was performed using the EXPGUI interface of GSAS. ${ }^{5}$ A pseudo Voigt function was used to model the peak shape. The angular range employed in the refinements was from $6^{\circ}$ to $35^{\circ} 2 \theta$, and excluded the regions that contained strong Bragg peaks from the pressure cell gasket.

Inspection of the variable pressure data above $4.3 \mathrm{GPa}$ indicated that the diffraction peaks of certain reflections began to split. An example of this peak splitting is the 620 peak in space group $F m \overline{3} m$ near $27.2^{\circ} 2 \theta$. Fig. 1 clearly shows the splitting of the peak at pressures of $5.6 \mathrm{GPa}$ and $6.3 \mathrm{GPa}$, compared to the single reflection at $4.3 \mathrm{GPa}$. The splitting of the reflections is well described by a cubic to tetragonal phase transition and is consistent with a phase transition to either space group P4/mnc or $I 4 / \mathrm{m}^{2}$ Reflections that violate the body centering conditions, such as the 212 reflection shown to be indicative ${ }^{6}$ of primitive symmetry in $\mathrm{Ba}_{2} \operatorname{PrIr}_{1}{ }_{x} \mathrm{Ru}_{x} \mathrm{O}_{6}$, were absent. Refinements were attempted using structure models generated by the SPuDS software in space groups $I 4 / m$ and $P 4 / m n c .{ }^{1}$ The fit was superior in space group $14 / \mathrm{m}$ compared to $P 4 / m n c$. A phase transition from cubic $(F m \overline{3} m)$ to tetragonal $(I 4 / m)$ was also reported ${ }^{7}$ to occur at 253(1) K; therefore the pressure induced phase transition from $F m \overline{3} m$ to $I 4 / m$ is the same as that which occurs on lowering of the temperature. Crystal structures shown in Fig. 2 were refined from the $4.3 \mathrm{GPa}$ and $6.3 \mathrm{GPa}$ data in space groups $F m \overline{3} m$ and $I 4 / m$, respectively.

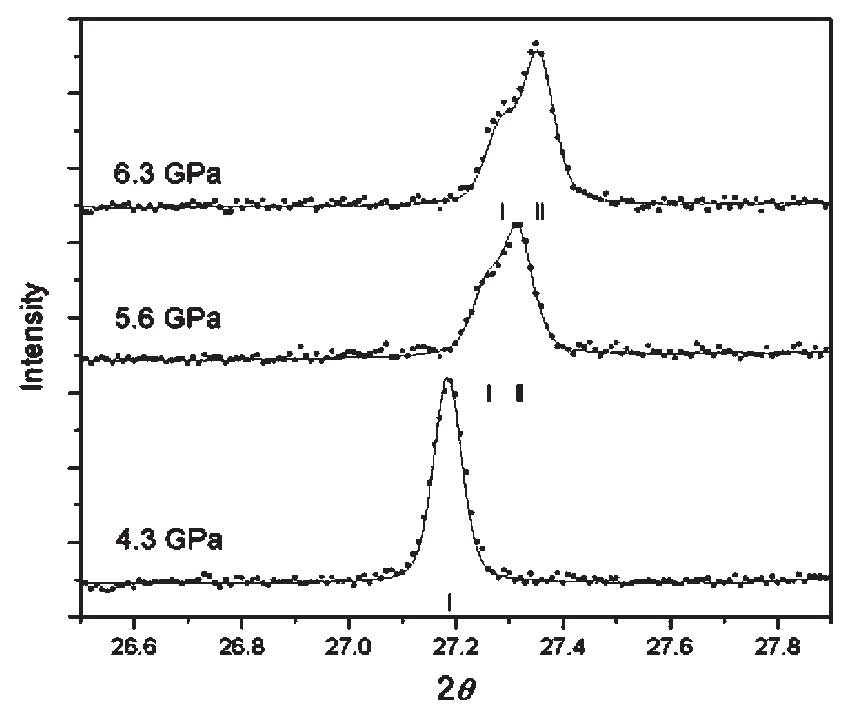

Fig. 1 Splitting of the 620 peak in $F m 3 m$ to the 116/332/240 peaks in $I 4 / m$ at $P=4.3,5.6$ and $6.3 \mathrm{GPa}$. The bottom pattern was fitted with space group $F m 3 m$, the top and middle patterns with $I 4 / m$. 


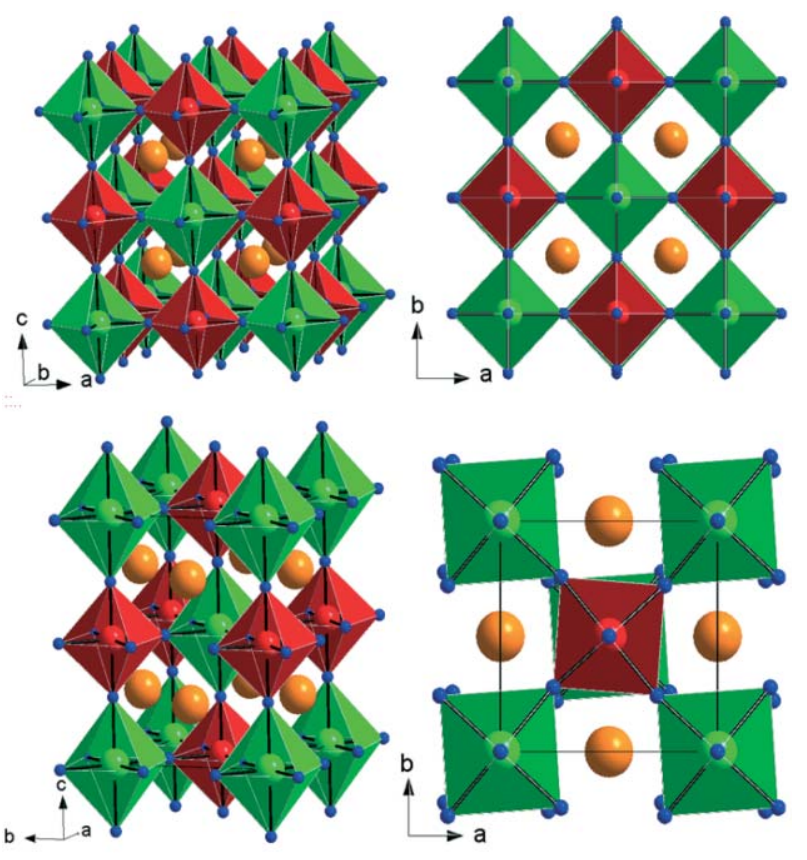

Fig. 2 Crystal structures of the $F m 3 m$ (top) and $I 4 / m$ (bottom) forms of $\mathrm{Ba}_{2} \mathrm{YTaO}_{6}$. Large orange spheres represent $\mathrm{Ba}$, green spheres $\mathrm{Y}$, red spheres are $\mathrm{Ta}$, and blue spheres $\mathrm{O}$.

This pressure induced phase transition is most clearly under stood in terms of an octahedral tilting distortion. The untilted ideal cubic ordered double perovskite crystallizes in space group $F m \overline{3} m$. In space group $I 4 / m$, an antiphase octahedral tilting distortion occurring about the $c$ axis is clearly shown in Fig. 2. The octahedral tilting phase transition allows for an additional means of compression of the structure. In perovskites, the two dominating processes during compression are bond shortening and octahedral tilting. In the cubic form of $\mathrm{Ba}_{2} \mathrm{YTaO}_{6}$, compres sion with retention of the cubic symmetry is possible only via the simultaneous shortening of the $\mathrm{Y} \mathrm{O}$, Ta $\mathrm{O}$ and $\mathrm{Ba} \mathrm{O}$ bonds. In its tetragonal form, on the other hand, both bond shortening and octahedral tilting can take place. However, while a decrease in the $c$ lattice parameter is the result of only the compressive shortening of the $\mathrm{Y} \mathrm{O}, \mathrm{Ta} \mathrm{O}$, and $\mathrm{Ba} \mathrm{O}$ bond distances, a reduction of the $a$ lattice parameter can have contributions from both bond compression and octahedral tilting.

In an ideal $I 4 / m$ perovskite crystal structure with symmetric octahedra and $0^{\circ}$ octahedral tilting, the $\sqrt{2} a$ and $c$ lattice parameters are equal and the $c /(\sqrt{2} 2 a)$ ratio is unity. The observation of a larger relative compression of the $a$ lattice parameter compared to the $c$ lattice parameter, that is when $c /(\sqrt{2} 2 a)$ becomes larger than unity, is indicative of an additional compression mechanism, namely octahedral tilting.

Octahedral tilting has a primary effect on the $\mathrm{Ba} \mathrm{O}$ bond lengths, with a minimal change in the octahedral cation bond lengths. If the octahedral bond distances remain regular, then with an increase in the magnitude of octahedral tilting the $a$ lattice parameter becomes smaller while the $c$ lattice parameter remains unchanged. Therefore, we can conclude that the observed increase in the $c /(\sqrt{2} 2 a)$ ratio in $\mathrm{Ba}_{2} \mathrm{YTaO}_{6}$ from 1.0025 to 1.0029 upon a change in the applied pressure from 5.6 to $6.3 \mathrm{GPa}$, represents a
Table 1 Pressure dependence of the lattice parameters and unit cell volume

\begin{tabular}{|c|c|c|c|c|}
\hline Pressure/GPa & Space group & $a / \AA ̊$ & $c / \AA ̊$ & Volume $/ \AA^{3}$ \\
\hline 0.9 & $F m 3 m$ & $8.42811(8)$ & & $598.67(2)$ \\
\hline 1.7 & $F m 3 m$ & $8.4077(2)$ & & $594.33(5)$ \\
\hline 2.2 & $F m 3 m$ & $8.39707(8)$ & & $592.08(2)$ \\
\hline 3.1 & $F m 3 m$ & $8.38092(9)$ & & $588.67(2)$ \\
\hline 4.3 & $F m 3 m$ & $8.37435(9)$ & & $587.29(2)$ \\
\hline 5.6 & $I 4 / m$ & $5.8928(2)$ & $8.3545(4)$ & $290.11(2)$ \\
\hline 6.3 & $I 4 / m$ & $5.8851(1)$ & $8.3474(2)$ & 289.10(1) \\
\hline
\end{tabular}

greater degree of octahedral tilting. The average tilt angle of the $\left[\mathrm{YO}_{6}\right]$ and $\left[\mathrm{TaO}_{6}\right]$ octahedra is $4.1^{\circ}$ at $6.3 \mathrm{GPa}$.

One cause for such a tilting transition is a difference in the relative compressibilities of the $\mathrm{A} X$ vs. $\mathrm{B} X$ bonds in an $\mathrm{ABX}_{3}$ perovskite. For example, a recent study of the perovskite $\mathrm{NaMgF}_{3}$ demonstrated that the compression mechanism was dominated by a shortening of the $\mathrm{Mg} \mathrm{F}$ bonds below $6 \mathrm{GPa}$ and controlled by an increase in octahedral tilting above $12 \mathrm{GPa}$; however, in that experiment no change in the type of octahedral tilting was observed. $^{8}$ We have obtained similar results in this study of $\mathrm{Ba}_{2} \mathrm{YTaO}_{6}$, where bond compression is the dominant mechanism at lower pressures, while octahedral tilting becomes more important at higher pressures. These results also suggest that the $\mathrm{Ba} \mathrm{O}$ bonds are more compressible than the $\mathrm{Ta} \mathrm{O}$ and $\mathrm{Y} \mathrm{O}$ bonds, which is evident in the onset of the octahedral tilting transition.

The pressure dependence of the lattice parameters and unit cell volume is given in Table 1. Additional information on the Rietveld refinements in space group $F m \overline{3} m$ and in space group $I 4 / m$ at 6.3 $\mathrm{GPa}$ are given in the ESI. $\dagger$ Group theoretical analysis has shown the $F m \overline{3} m$ to $I 4 / m$ phase transition can be continuous. ${ }^{2}$ The pressure dependence of the lattice parameters is shown in Fig. 3. A second order Birch Murnaghan equation of state was fit to the pressure dependence of the unit cell volume data between 0.9 and 4.3 GPa, giving a bulk modulus of $157(16) \mathrm{GPa}$ and $V_{\mathrm{o}}$ 601.0(9) $\AA^{3}$. The bulk modulus is comparable to that found in other double perovskites, for example $\mathrm{Ba}_{2} \mathrm{BiTaO}_{6}$ at $126(10) \mathrm{GPa},{ }^{3}$

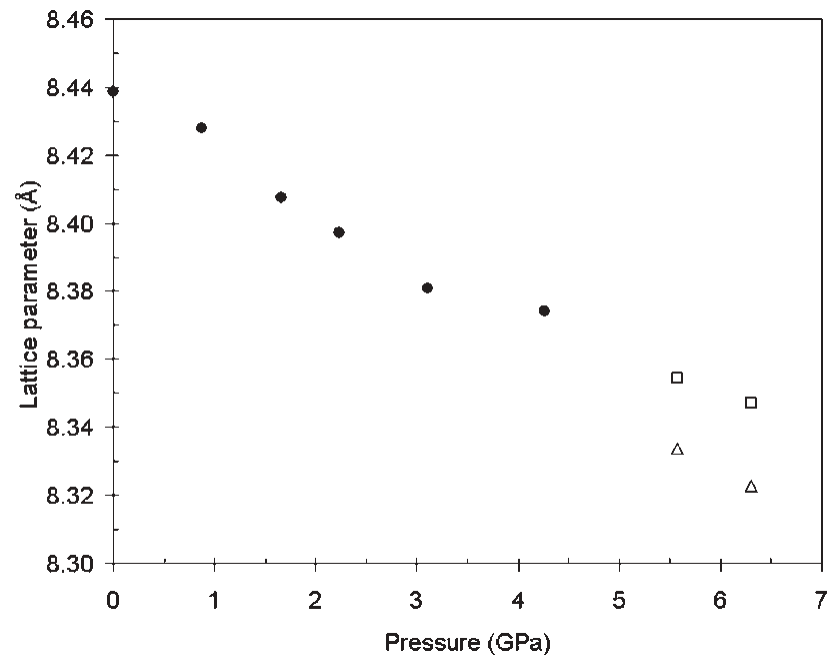

Fig. 3 Pressure variation of the lattice parameters. Circles represent $a$ in $F m 3 m$, squares $c$ in $I 4 / m$, and triangles $\sqrt{2} a$ in $I 4 / m$. 
$\mathrm{Ba}_{2} \mathrm{PrRu}_{0.8} \mathrm{Ir}_{0.2} \mathrm{O}_{6}$ at $139(10) \mathrm{GPa},{ }^{9}$ and $\mathrm{Sr}_{2} \mathrm{TbRu}_{0.3} \mathrm{Ir}_{0.7} \mathrm{O}_{6}$ at 196(10) GPa. ${ }^{10}$

In conclusion, we have demonstrated that a phase transition from space group $F m \overline{3} m$ to $I 4 / m$ occurs upon application of pressure to $\mathrm{Ba}_{2} \mathrm{YTaO}_{6}$ with the onset of an octahedral tilting distortion about the $c$ axis. The phase transition to space group $I 4 / m$ marks an additional compression mechanism consisting of simultaneous octahedral tilting and bond shortening in contrast to bond shortening only in space group $F m \overline{3} m$.

\section{Notes and references}

* Polycrystalline $\mathrm{Ba}_{2} \mathrm{YTaO}_{6}$ was prepared using solid state techniques by reacting $\mathrm{Y}_{2} \mathrm{O}_{3}$ and $\mathrm{Ta}_{2} \mathrm{O}_{5}$ to form a phase pure $\mathrm{YTaO}_{4}$ precursor, which was then appropriately mixed with $\mathrm{BaCO}_{3}$ and reacted until a single phase sample of $\mathrm{Ba}_{2} \mathrm{YTaO}_{6}$ was obtained, as established by laboratory powder $\mathrm{X}$ ray diffraction. The laboratory $\mathrm{X}$ ray powder diffraction pattern could be indexed with a cubic cell, space group Fm $3 m$, with $a \approx 8.42 \AA$.

$\S$ Work at Brookhaven is supported by the U.S. Department of Energy, Division of Materials Sciences, under Contract DE AC02 98CH10886.

Financial support from the Department of Energy through grant
DE FG02 04ER46122 and the National Science Foundation through grant DMR:0450103 is gratefully acknowledged.

1 M. W. Lufaso and P. M. Woodward, Acta Crystallogr., Sect. B: Struct. Sci., 2001, 57, 725.

2 P. M. Woodward, Acta Crystallogr., Sect. B: Struct. Sci., 1997, 53, 32; C. J. Howard, B. J. Kennedy and P. M. Woodward, Acta Crystallogr., Sect. B: Struct. Sci., 2003, B59, 463.

3 K. S. Wallwork, B. J. Kennedy, Q. D. Zhou, Y. Lee and T. Vogt, J. Solid State Chem., 2005, 178, 207.

4 T. Vogt, G. Schneider, J. A. Hriljac, G. Yang and J. S. Abell, Phys. Rev. B: Condens. Matter, 2001, 63, 22050.

5 A. C. Larson and R. B. von Dreele, General Structure Analysis System (GSAS), Los Alamos National Laboratories, 1990.

6 L. Q. Li and B. J. Kennedy, J. Solid State Chem., 2004, 177, 3290.

7 R. Zurmuhlen, E. Colla, D. C. Dube, J. Petzelt, I. Reaney, A. Bell and N. Setter, J. Appl. Phys., 1994, 76, 5864.

8 H. Z. Liu, J. Chen, J. Hu, C. D. Martin, D. J. Weidner, D. Hausermann and H. K. Mao, Geophys. Res. Lett., 2005, 32, L03404.

9 B. J. Kennedy, L. Q. Li, Y. Lee and T. Vogt, J. Phys.: Condens. Matter, 2004, 16, 3295.

10 Q. Zhou, B. J. Kennedy, K. S. Wallwork, M. M. Elcombe, Y. Lee and T. Vogt, J. Solid State Chem., 2005, 178, 2282. 